\title{
A new weapon for the interstellar complex organic molecule hunt: the minimum energy principle
}

\author{
M. Lattelais ${ }^{1}$, F. Pauzat ${ }^{1}$ Y. Ellinger ${ }^{1}$, and C. Ceccarelli ${ }^{2}$ \\ 1 UPMC Univ. Paris 06, UMR - CNRS 7616, Laboratoire de Chimie Théorique, 75005 Paris, France \\ e-mail: pauzat@lct.jussieu.fr \\ ${ }^{2}$ Laboratoire d'Astrophysique, Observatoire de Grenoble, 38041 Grenoble, France
}

Received 14 December 2009 / Accepted 14 May 2010

\section{ABSTRACT}

\begin{abstract}
Context. The hunt for the interstellar complex organic molecules (COMs) supposed to be the building blocks of the molecules at the origin of life is a challenging but very expensive task. It starts with laboratory experiments, associated with theoretical calculations, that give the line frequencies and strengths of the relevant molecules to be identified and finishes with observations at the telescopes. Aims. The present study aims to suggest possible guidelines to optimize this hunt. Levering on the minimum energy principle (MEP) presented in a previous study, we discuss the link between thermodynamic stability and detectability of a number of structures in the important families of amides, sugars and aminonitriles.

Methods. The question of the relative stability of these different species is addressed by means of quantum density functional theory simulations. The hybrid B3LYP formalism was used throughout. All 72 molecules part of this survey were treated on an equal footing. Each structure, fully optimized, was verified to be a stationary point by vibrational analysis.

Results. A comprehensive screening of 72 isomers of $\mathrm{CH}_{3} \mathrm{NO}, \mathrm{C}_{2} \mathrm{H}_{5} \mathrm{NO}, \mathrm{C}_{3} \mathrm{H}_{7} \mathrm{NO}, \mathrm{C}_{2} \mathrm{H}_{4} \mathrm{O}_{2}, \mathrm{C}_{3} \mathrm{H}_{6} \mathrm{O}_{3}$ and $\mathrm{C}_{2} \mathrm{H}_{4} \mathrm{~N}_{2}$ chemical formula has been carried out. We found that formamide, acetamide and propanamide (the first two identified in the Inter-Stellar Medium) are the most stable compounds in their families demonstrating at the same time that the peptide bond $>\mathrm{N}-\mathrm{C}=\mathrm{O}$ at the origin of life is the most stable bond that can be formed. Dihydroxyacetone, whose detection awaits for confirmation, is far from being the most stable isomer of its family while aminoacetonitrile, that has been recently identified, is effectively the most stable species.

Conclusions. The MEP appears to be a useful tool for optimizing the hunt for new species by identifying the potentially more abundant isomers of a given chemical formula.
\end{abstract}

Key words. ISM: molecules - ISM: abundances

\section{Introduction}

Beyond all philosophical connotations, the pursuit of the origin of life in extraterrestrial environments has never ceased to attract the attention of the scientific community, fueling the imagination of men for generations. Already proposed by Richter in 1865 and further developed by Arrhenius in 1903, the panspermia hypothesis, which claims that the seeds of life are present all over the Universe, was boosted by the discovery of the first organic molecules in the interstellar medium. However, the role of these molecules in the appearance of life on Earth and, more generally, in the Universe is still far from proven. Nonetheless, understanding what is the level of molecular complexity that can be reached in space is certainly a fundamental information and a major open question for modern astro -physics and -chemistry.

Among the most exciting species discovered, one may consider the first aldehyde $\mathrm{H}_{2} \mathrm{CO}$ (Snyder et al. 1969), the first alcohol $\mathrm{CH}_{3} \mathrm{OH}$ (Ball et al. 1970), the first conjugated molecule $\mathrm{HC}_{3} \mathrm{~N}$ (Turner 1971), the first acid $\mathrm{HCOOH}$ (Zuckerman et al. 1971) and the first alkyl cyanide $\mathrm{CH}_{3} \mathrm{CN}$ (Solomon et al. 1971). It is also the time when formamide $\mathrm{NH}_{2} \mathrm{CHO}$, the simplest model of the peptide bond was identified in Sgr B2 (Rubin et al. 1971).

In the following thirty years, more and more Complex Organic Molecules (hereafter referred to as COMs) have been shown to survive in different astrophysical environments. Among the extra-solar objects, the Galactic Center Molecular
Clouds (Requena-Torres et al. 2006; Hollis et al. 2006a), Hot Cores (Ikeda et al. 2001) and Hot Corinos (Bottinelli et al. 2007) are particularly rich in COMs.

It is worth noticing that, of the $\sim 150$ species identified up to today, more than 50 are composed of at least 6 atoms and present the main functional groups necessary to initiate a complex organic chemistry. It is indeed very likely, if not sure, that the COMs so far detected only represent the tip of the iceberg, and that many more complex molecules are synthesized in space. However, the detection of new species is a lengthy process, which involves more than just going to the astronomical observatories. In the vast majority, interstellar species are discovered in space by detection of their rotational lines in the radio to sub-millimeter. The more complex the molecule, the larger the number of the lines, caused by the rotation, bending and torsion of the different pieces of the molecule. The first difficulty is indeed to know what lines to observe to identify the target molecule, namely to know its line spectrum. Actually, in addition to know where the lines lie (in frequency), association with the relevant transition is needed, as much as the knowledge of the line strength. This is a very time-consuming and difficult task, which requires specific skills from spectroscopists and theoreticians. So far, in many cases, it is the lack of spectroscopic information which likely limits the search for new species in space. Published unbiased spectral surveys, in fact, often report a large fraction of unidentified lines. 
The scope of this article is to suggest guidelines for "optimizing" the hunt of new species, by identifying the potentially more abundant isomers of a given chemical formula. Our guidelines are based on the minimum energy principle (MEP), that we presented in a recent paper (Lattelais et al. 2009). Briefly, the analysis of several species observed in different environments (Molecular clouds, Hot Core/Hot Corinos, Photo-Dissociation Regions and AGB stars) has shown that the most abundant isomers of a same chemical formula are the most stable ones, with only two exceptions over a sample of 14 species under 32 different isomeric forms. In addition, the relative abundance ratio between the most stable and the different isomers appears closely correlated to the energy difference between the two isomers. We called this the MEP. The reason for the existence of MEP in space is not obvious, but this seems to be an observational fact that can be used as such.

Following up, we present here computations of the thermodynamic stability of COMs believed to be potentially important for the emergence of life. We considered several important families: amides, sugars and aminonitriles. In the present article we present a systematic survey of the stability of 72 isomers of these families by means of quantum chemical simulations. Considering that the case of glycine, prototype amino acid whose detection has become a graal for the community, deserves special attention, we chose to present it separately (Lattelais et al. in prep.).

The methodology is summarized in Sect. 2, the results for each of the above families of molecules are reported in Sect. 3, the discussion of the consequences of our computations is presented in Sect. 4.

\section{Computational background}

The argumentation developed in the following sections relies on the relative positions of isomers on the energy scale, so particular attention has to be given to the methods used for their calculation. In an ideal situation, we would have used the highest possible level of post Hartree-Fock theory with extended basis sets. However, in view of the large number of systems (with chemical size up to 12 atoms) to consider, a compromise had to be made between the level of theory and the computational requirements. This is the reason why density functional theory (DFT) was employed using the hybrid B3LYP formalism (Becke 1993; Lee et al. 1988) coupled with the standard 6-311G(d,p) basis set. This level of theory was designed for the best reproduction of the structural properties, energies and spectroscopic parameters (vibrations, dipole moments, ... ) of "normal" organic molecules, that is to say, molecules well represented by a unique Lewis structure.

On the other hand, it is known that it is not appropriate for the study of the species that can be described by more than one mesomeric formula like carbon clusters. In this respect, the case of $\mathrm{C}_{3} \mathrm{H}$ is illustrative with a swap in the energies of linear and cyclic structures between B3LYP and CCSD(T) calculations (see Appendix A below). This level of theory would not be relevant either for the study of weak interactions, like adsorption at the surface of interstellar grains, because of a wrong behavior of the exchange-correlation functional at large atomic separation and the PW91 (or similar functionals) should be preferred in this case (see for example Wesolowski et al. 1997; Zhang, et al. 1997; Wesolowski 2000).

The extension of the basis set is less important for DFT than for configuration interaction treatments; more than 15 years of experience have shown that a correct description of the electronic densities is already obtained with atomic expansions of triple zeta quality (see for example Martin et al. 1996). It is worth noting that this same B3LYP functional, with equivalent basis set, has been recently used for a study of the photophysics of acetic acid and its isomers (Puletti et al. 2010). For a comprehensive presentation of DFT methods and their applicability, the reader may profitably refer to Lee \& Scuseria (1995) and Koch $\&$ Holthausen (2001).

In the present work, each structure, fully optimized, was verified to be a stationary point by vibrational analysis. All conformers were studied for each molecule but only the most stable one is reported here. Selected structural parameters are given in Appendix B for the most stable isomer of each family (presenting structural details as well as spectroscopic constants and IR signatures for all the calculated structures is beyond the scope of this article and will be addressed in a forthcoming paper). All the energy differences include the zero point vibrational energy (ZPE). We have verified that including entropic terms to determine Gibbs free energies of formation at the temperature usually considered in the ISM has a marginal impact on the values of the energy differences.

The accuracy of the energetic data has been checked with respect to both the extension of the basis set and the treatment of the electronic correlation on the series of 32 isomers considered in our preceding study (Lattelais et al. 2009). (supporting data are given in Appendix A). Increasing the flexibility of the basis set from triple to quadruple zeta has a marginal effect in our B3LYP calculations. Comparison of the B3LYP/6-311(d,p) energy differences with the results obtained at the "state of the art" coupled cluster (CCSD(T)/cc-pVQZ level of theory taken as reference, points to an average discrepancy of $1.7 \mathrm{kcal} / \mathrm{mol}$. The ordering of the isomers on the energy scale is maintained for all systems but one: $\mathrm{C}_{3} \mathrm{H}$. In this particular and only case, the $\operatorname{CCSD}(\mathrm{T})$ level of theory is necessary to assess the greater stability of the cyclic over the linear structure. At all events, the energy gap is small and concerns non-classical chemical structures. The relative energies reported here for systems with standard bonding should be accurate within $\sim 2 \mathrm{kcal} / \mathrm{mol}$.

All the calculations were performed using the GAUSSIAN03 package (Frisch et al. 2004).

\section{Molecules with the peptide bond}

Among the possible interstellar molecules, those containing the four most abundant atoms vital for life on Earth, namely $\mathrm{H}, \mathrm{N}$, $\mathrm{O}$ and $\mathrm{C}$, are of major interest. The interest is even larger for molecules with a peptide bond (the group $\mathrm{CO}-\mathrm{NH}$ ), as the large chains of amino acids forming proteins are glued together by this bond. The question here is: what are the most stable molecules, having the potential to form a precious peptide bond? To answer this question, we explore three groups with an increasing number of carbon atoms.

\subsection{The $\mathrm{CH}_{3} \mathrm{NO}$ isomers}

A previous study of the stability of the peptide bond (Chiaramello et al. 2005) has shown that formamide $\mathrm{NH}_{2} \mathrm{CHO}$, the first step on the protein route, is the lowest energy isomer of the generic formula $\mathrm{CH}_{3} \mathrm{NO}$. Up to now, it is the only $\mathrm{CH}_{3} \mathrm{NO}$ isomer detected in the interstellar medium (Rubin et al. 1971). We also studied the stability of all other possible isomers. A summary of our computations is given in Table 1 . 
Table 1. Computed relative stabilities $(\mathrm{kcal} / \mathrm{mol})$ and dipole moments (Debye) of formamide isomers.

\begin{tabular}{|c|c|c|}
\hline Molecule & $\mu$ & $\overline{\Delta E}$ \\
\hline $\mathrm{NH}_{2}$-CHO & 3.9 & 0.0 \\
\hline $\mathrm{NHCHOH}$ & 1.0 & 13.4 \\
\hline $\mathrm{CH}_{2} \mathrm{NOH}$ & 0.2 & 51.0 \\
\hline $\mathrm{CH}_{3} \mathrm{NO}$ & 2.4 & 62.8 \\
\hline $\mathrm{CH}_{2} \mathrm{NHO}$ & 3.4 & 61.6 \\
\hline$\stackrel{\mathrm{H}}{\mathrm{s}}$ & 2.6 & 74.1 \\
\hline
\end{tabular}

There are six stable isomers, five of which have a linear backbone of the three heavy atoms, the last one being a cyclic molecule. Formamide is unambiguously the most stable one. The next isomer on the energy scale is $\mathrm{HN}=\mathrm{CH}-\mathrm{OH}$; it is the enol form of formamide $\sim 13 \mathrm{kcal} / \mathrm{mol}$ higher in energy. The third isomer $\mathrm{H}_{2} \mathrm{C}=\mathrm{NOH}$ is formaldoxime. The next two isomers are nitrogen oxides, i.e. nitrosomethane $\mathrm{CH}_{3} \mathrm{~N}=\mathrm{O}$ and the corresponding nitrone $\mathrm{H}_{2} \mathrm{C}=\mathrm{NHO}$. The last isomer is a three-membered ring, more than $70 \mathrm{kcal} / \mathrm{mol}$ above formamide.

It should be noted that the isomers with $\mathrm{N}-\mathrm{C}-\mathrm{O}$ connectivity, i.e. those leading to the prebiotic structures are by far the most stable ones. By contrast, connectivities with a NO bond are more than $50 \mathrm{kcal} / \mathrm{mol}$ higher than formamide.

The energy difference between formamide and its enol form is similar to that between acetaldehyde $\mathrm{CH}_{3} \mathrm{CHO}$ and $\mathrm{H}_{2} \mathrm{C}=\mathrm{CHOH}$. In addition, the dipole moments of the two enols are $\sim 1$ Debye. In these conditions, it is reasonable to think that $\mathrm{HN}=\mathrm{CH}-\mathrm{OH}$ should be the next species to be seen in this family with an abundance ratio $\mathrm{NH}_{2} \mathrm{CHO} / \mathrm{HN}=\mathrm{CH}-\mathrm{OH}$ probably close to $\mathrm{CH}_{3} \mathrm{CHO} / \mathrm{H}_{2} \mathrm{C}=\mathrm{CHOH}$, namely between 2 and 10 .

\subsection{The $\mathrm{C}_{2} \mathrm{H}_{5} \mathrm{NO}$ isomers}

A complete study of 13 isomers, including all those of prebiotic interest, has been carried out that gave the energetic ordering reported in Table 2.

The two isomers of lower energy contain the peptide bond. The most stable one, acetamide $\mathrm{CH}_{3} \mathrm{CONH}_{2}$, has been recently observed in Sgr B2 (Hollis et al. 2006b) and remains, to our knowledge, the only isomer observed. N-methyl formamide, $\mathrm{CH}_{3} \mathrm{NHCHO}$, is next on the energy scale $\sim 10 \mathrm{kcal} / \mathrm{mol}$ higher. In third position, one finds the enolic form of acetamide, $\mathrm{CH}_{3} \mathrm{COH}=\mathrm{NH}, \sim 13 \mathrm{kcal} / \mathrm{mol}$ above its parent system. These three low energy isomers have the same N-C-O connectivity.

An interesting result concerning this series is that all species containing the NO bond are $\sim 60 \mathrm{kcal} / \mathrm{mol}$ above acetamide. According to the MEP, they can hardly be considered as plausible candidates for detection in the Inter-Stellar Medium. In these conditions, N-methyl formamide, with a dipole moment of $\sim 4$ Debye, close to that of acetamide, should be the next molecule that contains the peptide bond to be detected in space. If both amides were to be seen, it would establish that the complexity of the peptide bond can progress on both sides ( $\mathrm{N}$ and $\mathrm{C}$ ) of the $\mathrm{C}-\mathrm{N}-\mathrm{O}$ linkage. It is also worth noting that amino acetaldehyde $\mathrm{NH}_{2} \mathrm{CH}_{2} \mathrm{CHO}$, a precursor of glycine $\mathrm{NH}_{2} \mathrm{CH}_{2} \mathrm{COOH}$, is more than $\sim 25 \mathrm{kcal} / \mathrm{mol}$ above the lowest energy structure.
Table 2. Computed relative stabilities $(\mathrm{kcal} / \mathrm{mol})$ and dipole moments (Debye) of acetamide isomers.

\begin{tabular}{|c|c|c|}
\hline Molecule & $\overline{\mu \mu}$ & 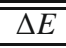 \\
\hline $\begin{array}{c}\mathrm{H}_{3} \mathrm{C}-\mathrm{C}-\mathrm{NH}_{2} \\
\mathrm{O}\end{array}$ & 3.8 & 0.0 \\
\hline$\underset{\mathrm{O}}{\mathrm{H}} \mathrm{H}_{3} \mathrm{C}-\mathrm{NH}-\mathrm{CH}$ & 3.9 & 10.1 \\
\hline $\begin{array}{c}\mathrm{H}_{3} \mathrm{C}-\mathrm{C}=\mathrm{NH} \\
\mathrm{OH}\end{array}$ & 1.5 & 13.3 \\
\hline $\mathrm{HO}-\mathrm{CH}=\mathrm{N}-\mathrm{CH}_{3}$ & 0.8 & 23.1 \\
\hline $\begin{array}{c}\mathrm{H}_{2} \mathrm{C}=\mathrm{C}-\mathrm{NH}_{2} \\
\mathrm{OH}\end{array}$ & 1.1 & 26.1 \\
\hline $\mathrm{H}_{2} \mathrm{~N}-\mathrm{CH}_{2}-\underset{\mathrm{O}}{\mathrm{CH}}$ & 1.6 & 26.1 \\
\hline $\mathrm{H}_{3} \mathrm{C}-\mathrm{O}-\mathrm{CH}=\mathrm{NH}$ & 0.7 & 28.1 \\
\hline $\mathrm{HO}-\mathrm{CH}=\mathrm{CH}-\mathrm{NH}_{2}$ & 2.3 & 32.0 \\
\hline $\mathrm{CH}_{2}=\mathrm{NOCH}_{3}$ & 0.2 & 63.5 \\
\hline $\mathrm{CH}_{3} \mathrm{CH}_{2} \mathrm{NO}$ & 2.5 & 67.0 \\
\hline & 2.5 & 72.5 \\
\hline $1 /$ & 2.5 & 80.0 \\
\hline $\mathrm{CH}_{3} \mathrm{CH}=\mathrm{NHO}$ & 1.6 & 88.8 \\
\hline
\end{tabular}

\subsection{The $\mathrm{C}_{3} \mathrm{H}_{7} \mathrm{NO}$ isomers}

Adding one more carbon and two hydrogen atoms is one step further towards complexity. The same systematic study of 25 isomers of prebiotic interest was carried out, leading to the relative energies reported in Table 3.

As already noted for the smaller systems, the isomers of lower energy contain the peptide bond. All three are within $\sim 9 \mathrm{kcal} / \mathrm{mol}$ from the most stable one: propanamide. The presence of alkyl substituents on the carbonyl group $(>\mathrm{C}=\mathrm{O})$ has a stabilizing effect whereas it is a destabilizing factor when they are attached to the amino group $(>\mathrm{NH})$. It is illustrated by the higher energy of aldehydes compared to ketones. The enolic structures are more than $\sim 15 \mathrm{kcal} / \mathrm{mol}$ above their carbonyl parents. As observed previously, the molecules containing the NO bond are $\sim 50-65 \mathrm{kcal} / \mathrm{mol}$ above the most stable species. The first cyclic molecule is a five membered ring, but its high energy ( $\sim 0 \mathrm{kcal} / \mathrm{mol}$ above propanamide) makes it an unlikely candidate for detection in the ISM. It is also true of the three membered rings that are more than $\sim 25 \mathrm{kcal} / \mathrm{mol}$ higher, as in the one and two carbon series.

The three amides have dipole moments close to $\sim 4$ Debye. The detection of $\mathrm{CH}_{3} \mathrm{CONHCH}_{3}$, although not the most stable isomer, would be an important step in complexity since it is the first symmetric peptide.

\section{Carbohydrates (or sugars)}

Carbohydrates, better known under the name of sugars are among the key molecules, together with phosphorus compounds and nucleic bases, for the emergence of a DNA world. Their general formula $\mathrm{C}_{n}\left(\mathrm{H}_{2} \mathrm{O}\right)_{n}$ shows that they are composed of as many molecules of water as the number of carbon atoms they contain. These molecules belong in two types according to the nature of their carbonyl group: either aldoses, with 
Table 3. Computed relative stabilities $(\mathrm{kcal} / \mathrm{mol})$ and dipole moments (Debye) of propanamide isomers.

\begin{tabular}{|c|c|c|}
\hline Molecule & $\mu$ & $\overline{\overline{\Delta \Delta E}}$ \\
\hline$\underset{\mathrm{O}}{\mathrm{CH}_{3} \mathrm{CH}_{2}-\mathrm{CH}_{2}-\mathrm{NH}_{2}}$ & 3.6 & 0.0 \\
\hline $\begin{array}{l}\mathrm{CH}_{3}-\mathrm{C}-\mathrm{NH}-\mathrm{CH}_{3} \\
\mathrm{O}\end{array}$ & 3.7 & 4.1 \\
\hline $\mathrm{CH}_{3} \mathrm{CH}_{2}-\mathrm{NH}-\mathrm{CH}$ & 3.8 & 8.7 \\
\hline$\underset{\mathrm{O}}{\mathrm{CH}_{3}-\mathrm{C}-\mathrm{CH}_{2}-\mathrm{NH}_{2}}$ & 2.1 & 18.7 \\
\hline $\begin{array}{c}\mathrm{CH}_{3}-\mathrm{C}=\mathrm{N}-\mathrm{CH}_{3} \\
\mathrm{OH}\end{array}$ & 1.2 & 18.9 \\
\hline $\begin{array}{c}\mathrm{CH}_{3}-\mathrm{O}-\mathrm{C}=\mathrm{NH} \\
\mathrm{CH}_{3}\end{array}$ & 1.2 & 22.4 \\
\hline $\begin{array}{c}\mathrm{NH}_{2}-\mathrm{CH}-\mathrm{CH}=\mathrm{O} \\
\mathrm{CH}_{3}\end{array}$ & 1.7 & 24.5 \\
\hline $\begin{array}{c}\mathrm{CH}_{3}-\mathrm{CH}=\mathrm{C}-\mathrm{NH}_{2} \\
\mathrm{OH}\end{array}$ & 0.8 & 26.0 \\
\hline$\underset{\mathrm{O}}{\mathrm{HC}}-\mathrm{CH}_{2}-\mathrm{CH}_{2}-\mathrm{NH}_{2}$ & 2.0 & 26.0 \\
\hline $\begin{array}{c}\mathrm{HO}-\mathrm{CH}=\mathrm{C}-\mathrm{NH}_{2} \\
\mathrm{CH}_{3}\end{array}$ & 2.5 & 28.4 \\
\hline $\begin{array}{c}\mathrm{CH}_{2}=\mathrm{C}-\mathrm{CH}_{2}-\mathrm{NH}_{2} \\
\stackrel{\mathrm{OH}}{ }\end{array}$ & 3.5 & 31.0 \\
\hline $\begin{aligned} \mathrm{CH}_{2} & =\mathrm{C}-\mathrm{NH}-\mathrm{CH}_{3} \\
& \mathrm{OH}\end{aligned}$ & 1.0 & 31.0 \\
\hline $\mathrm{HO}-\mathrm{CH}=\mathrm{CH}-\mathrm{CH}_{2}-\mathrm{NH}_{2}$ & 2.9 & 31.3 \\
\hline $\mathrm{CH}_{3}-\mathrm{O}-\mathrm{CH}=\mathrm{NCH}_{3}$ & 0.3 & 31.8 \\
\hline$\underset{\mathrm{O}}{\mathrm{HC}-\mathrm{CH}_{2}-\mathrm{NH}-\mathrm{CH}_{3}}$ & 1.7 & 32.5 \\
\hline $\mathrm{HO}-\mathrm{CH}=\mathrm{CH}-\mathrm{NH}-\mathrm{CH}_{3}$ & 2.1 & 37.7 \\
\hline & 2.1 & 40.4 \\
\hline $\begin{array}{c}\mathrm{CH}_{3}-\mathrm{C}=\mathrm{N}-\mathrm{OH} \\
\mathrm{CH}_{3}\end{array}$ & 0.7 & 47.0 \\
\hline $\begin{array}{c}\mathrm{CH}_{3}-\mathrm{C}=\mathrm{C} H-\mathrm{O} \\
\mathrm{C}_{3}\end{array}$ & 4.0 & 57.3 \\
\hline $\mathrm{CH}_{3}-\mathrm{CH}=\mathrm{N}-\mathrm{OCH}_{3}$ & 0.7 & 57.9 \\
\hline $\begin{array}{c}\mathrm{CH}_{3}-\mathrm{CH}=\underset{!}{\mathrm{N}}-\mathrm{CH}_{3} \\
\mathrm{O}\end{array}$ & 3.5 & 60.7 \\
\hline $\begin{array}{c}\mathrm{CH}_{3}-\mathrm{CH}-\mathrm{N}=\mathrm{O} \\
\mathrm{CH}_{3}\end{array}$ & 2.6 & 65.4 \\
\hline $\mathrm{H}_{3} \mathrm{C}$ & 2.7 & 67.2 \\
\hline $\mathrm{CH}_{3}$ & 2.4 & 72.6 \\
\hline${ }_{3}^{\mathrm{H}_{3} \mathrm{C}} \mathrm{C}_{\mathrm{H}}$ & 2.4 & 76.3 \\
\hline
\end{tabular}

an aldehyde group (-CHO) at the end of the carbon chain, $\mathrm{CH}_{2} \mathrm{OH}-(\mathrm{CHOH})_{n}-\mathrm{CHO}$, or ketoses with a ketone $\left(\mathrm{R}_{1} \mathrm{R}_{2}>\mathrm{CO}\right)$ group inside the carbon chain, $\mathrm{CH}_{2} \mathrm{OH}-(\mathrm{CHOH})_{n}-\mathrm{CO}-$ $(\mathrm{CHOH})_{m}-\mathrm{CH}_{2} \mathrm{OH}$. Finding any molecule of the sugar family is of utmost importance for prebiotic models.
Table 4. Computed relative stabilities $(\mathrm{kcal} / \mathrm{mol})$ and dipole moments (Debye) of $\mathrm{C}_{2}\left(\mathrm{H}_{2} \mathrm{O}\right)_{2}$ isomers.

\begin{tabular}{|c|c|c|}
\hline Molecule & $\bar{\mu}$ & 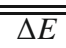 \\
\hline $\begin{array}{c}\mathrm{CH}_{3} \mathrm{C}-\mathrm{OH} \\
\mathrm{O}\end{array}$ & 1.6 & 0.0 \\
\hline $\begin{array}{l}\mathrm{HC}-\mathrm{OCH}_{3} \\
\mathrm{O}\end{array}$ & 1.8 & 16.0 \\
\hline$\stackrel{\mathrm{HO}-\mathrm{CH}_{2}-\mathrm{CH}}{\mathrm{O}}$ & 2.4 & 28.5 \\
\hline
\end{tabular}

\subsection{The $\mathrm{C}_{2}\left(\mathrm{H}_{2} \mathrm{O}\right)_{2}$ isomers}

The initial report of glycolaldehyde, $\mathrm{CH}_{2} \mathrm{OHCHO}$, the simplest possible aldose, (Hollis et al. 2000) was based on radio observations in the millimeter-wave range in the hot molecular core Sgr B2(N-LMH). It is the last isomer detected with this chemical formula. The two other isomers, acetic acid $\mathrm{CH}_{3} \mathrm{COOH}$ (Mehringer et al. 1997) and methyl formate $\mathrm{HCOOCH}_{3}$ (Brown et al. 1975) had been observed earlier in the ISM.

Applying an energetic criterion to the successive detections shows that $\mathrm{HOCH}_{2} \mathrm{CHO}$ is effectively the less stable of the three isomers, more than $\sim 25 \mathrm{kcal} / \mathrm{mol}$ above acetic acid (Table 4 ). We discussed the $\mathrm{C}_{2}\left(\mathrm{H}_{2} \mathrm{O}\right)_{2}$ isomers in our previous study (Lattelais et al. 2009), and found that this is one (and the clearest) of the two exceptions to the MEP, as the most abundant isomer of the three is the methyl formate rather than the acetic acid. The reason for this is not clear, but it could be linked to a stronger adsorption on the grains of the acetic acid than of the methyl formate, at the moment of their formation on the grain surfaces. Alternatively, the isomerization of these two species may be particularly difficult because it would require breaking two bonds simultaneously. A recent study of the photophysics of these isomers (Puletti et al. 2010) points also to the possible role of the radiation field. From a larger point of view, it will be interesting to understand whether the sugar group in general share the same problem.

\subsection{The $\mathrm{C}_{3}\left(\mathrm{H}_{2} \mathrm{O}\right)_{3}$ isomers}

Detection of dihydroxyacetone $\left(\mathrm{HOCH}_{2} \mathrm{COCH}_{2} \mathrm{OH}\right)$, DHA, has been claimed by Widicus Weaver \& Blake (2005) but soon after was challenged by Apponi et al. (2006).

What does the energetic criterion say in this case? The relative energies of the eight most stable isomers of DHA are given in Table 5. The two structures with the lowest energy are hydroxy carboxylic acids, both derived from propanoic acid; they are very close to each other. Lactic acid $\mathrm{HOCHMeCOOH}$, an important biological compound, is the most stable, $\sim 1 \mathrm{kcal} / \mathrm{mol}$ lower than 1-hydroxypropanoic acid $\mathrm{HOCH}_{2} \mathrm{CH}_{2} \mathrm{COOH}$. In third position, one has the first example of a new family of molecules, namely dimethyl carbonate only $\sim 6.5 \mathrm{kcal} / \mathrm{mol}$ above lactic acid. The next compound on the energy scale is the methyl ester of hydroxy acetic acid. The two sugars, dihydroxyacetone and glyceraldehyde come only in sixth and seventh positions, well above the carboxylic isomers. Finally, the cyclic trimer of formaldehyde is $\sim 12 \mathrm{kcal} / \mathrm{mol}$ higher than the sugars, that is $\sim 38 \mathrm{kcal} / \mathrm{mol}$ above the most stable species.

The basic trends shown by the $\mathrm{C}_{2}\left(\mathrm{H}_{2} \mathrm{O}\right)_{2}$ isomers are confirmed in the present series. The carboxylic acid is more stable than the methyl ester by more than $10 \mathrm{kcal} / \mathrm{mol}$. The two sugars are $\sim 24-26 \mathrm{kcal} / \mathrm{mol}$ above the most stable structure as $\mathrm{HOCH}_{2} \mathrm{CHO}$ is over $\mathrm{CH}_{3} \mathrm{COOH}$. (see Table 5). 
Table 5. Computed relative stabilities $(\mathrm{kcal} / \mathrm{mol})$ and dipole moments (Debye) of 1,3-dihydroacetone isomers.

\begin{tabular}{|c|c|c|}
\hline Molecule & $\mu$ & $\overline{\overline{\Delta E}}$ \\
\hline $\begin{array}{c}\mathrm{CH}_{3} \\
\text { HO-CH-C-OH } \\
\stackrel{\mathrm{O}}{\mathrm{O}}\end{array}$ & 2.3 & 0.0 \\
\hline$\underset{\mathrm{HO}-\mathrm{CH}_{2}-\mathrm{CH}_{2}-\mathrm{C}-\mathrm{OH}}{\mathrm{O}}$ & 2.6 & 0.9 \\
\hline $\begin{array}{c}\mathrm{CH}_{3}-\mathrm{O}-\mathrm{C}-\mathrm{OCH}_{3} \\
\mathrm{O}\end{array}$ & 0.3 & 6.6 \\
\hline $\begin{array}{c}\mathrm{CH}_{3}-\mathrm{O}-\mathrm{C}-\mathrm{CH}_{2}-\mathrm{OH} \\
\mathrm{O}\end{array}$ & 3.0 & 11.5 \\
\hline$\underset{\mathrm{O}}{\mathrm{CH}_{3}-\mathrm{O}-\mathrm{CH}_{2}-\mathrm{C}-\mathrm{OH}}$ & 1.9 & 13.4 \\
\hline $\begin{array}{c}\mathrm{HO}-\mathrm{CH}_{2}-\mathrm{C}_{\mathrm{O}}-\mathrm{CH}_{2} \mathrm{OH} \\
\mathrm{O}\end{array}$ & 1.6 & 23.5 \\
\hline$\stackrel{\mathrm{HO}}{\mathrm{HO}-\mathrm{CH}_{2}-\mathrm{C} H-\mathrm{O}_{\mathrm{O}}}$ & 2.1 & 26.3 \\
\hline & 2.0 & 37.8 \\
\hline
\end{tabular}

Based on the MEP, the two hydroxy carboxylic acids should be the most abundant among the series. However, since their energy difference is at the very limit of precision of the present computational experiment, it is safer to consider that they most probably have equivalent abundances. It is also possible that the same phenomenon that makes the methyl formate more abundant than the acetic acid is also at work here, and that, therefore, the most abundant of the series is the dimethyl carbonate.

\section{Amino acids precursors}

Amino acids are molecules containing both amine and carboxyl functional groups. The family of the $\alpha$ amino acids (where the amine and the carboxyl groups are attached by a carbon atom), whose generic formula is $\mathrm{H}_{2} \mathrm{NCHRCOOH}$ with $\mathrm{R}$ a generic organic group, is particularly important because these molecules are the building blocks of proteins. Given their supreme importance in terrestrial life, their presence in the interstellar medium has been long searched for, but without success so far, even for glycine, the simplest member of the family. On the other hand, several complex amino acids are found in the carbonaceous chondrites collected on Earth; for example, more than 70 of those species including 8 out of the 20 present in living organisms (Cooper et al. 1992) were isolated in the Murchison meteorite (fall in 1969). It is however worth noticing that those amino acids are thought to have been formed via aqueous alterations on the parent body.

If one considers that aminoacids are end products in the Inter-Stellar Medium, the presence of any of their precursors is equally important.

In a preceding section we have shown that $\mathrm{NH}_{2} \mathrm{CH}_{2} \mathrm{CHO}$, that would lead to glycine $\mathrm{NH}_{2} \mathrm{CH}_{2} \mathrm{COOH}$ by oxydation is $\sim 26 \mathrm{kcal} / \mathrm{mol}$ above the lowest energy structure of same chemical formula. Its abundance should be very small and its role as intermediate in the formation of glycine very unlikely.

On another hand, the Strecker synthesis has already been proposed to explain the formation of these species in meteorites (Peltzer et al. 1984; Ehrenfreund et al. 2001; Bernstein et al. 2004). A major intermediate step in the process is the formation
Table 6. Computed relative stabilities $(\mathrm{kcal} / \mathrm{mol})$ and dipole moments (Debye) of aminoacetonitrile isomers.

\begin{tabular}{|c|c|c|}
\hline$\overline{\text { Molecule }}$ & $\mu$ & $\overline{\Delta E}$ \\
\hline $\mathrm{NH}_{2}-\mathrm{CH}_{2}-\mathrm{CN}$ & 2.6 & 0.0 \\
\hline $\mathrm{CH}_{3}-\mathrm{NH}-\mathrm{CN}$ & 4.8 & 3.1 \\
\hline $\mathrm{CH}_{3}-\mathrm{N}=\mathrm{C}=\mathrm{NH}$ & 2.1 & 3.3 \\
\hline $\mathrm{HN}=\mathrm{CH}-\mathrm{CH}=\mathrm{NH}$ & 0.0 & 11.3 \\
\hline $\mathrm{HN}=\mathrm{CH}-\mathrm{N}=\mathrm{CH}_{2}$ & 2.8 & 13.6 \\
\hline $\mathrm{NH}_{2}-\mathrm{CH}_{2}-\mathrm{NC}$ & 2.7 & 18.5 \\
\hline $\mathrm{NH}_{2}-\mathrm{CH}=\mathrm{C}=\mathrm{NH}$ & 1.0 & 24.2 \\
\hline $\mathrm{CH}_{3}-\mathrm{CH}=\mathrm{N}=\mathrm{N}$ & 2.1 & 25.2 \\
\hline & 3.8 & 27.9 \\
\hline & 2.7 & 29.3 \\
\hline $\mathrm{CH}_{2}=\mathrm{N}-\mathrm{N}=\mathrm{CH}_{2}$ & 0.0 & 30.8 \\
\hline & 2.9 & 33.1 \\
\hline $\mathrm{NH}_{2}-\mathrm{C} \equiv \mathrm{C}-\mathrm{NH}_{2}$ & 1.4 & 33.8 \\
\hline$\underset{\mathrm{N}}{1}>\mathrm{CH}-\mathrm{CH}_{3}$ & 2.0 & 37.6 \\
\hline $\mathrm{H}_{2} \mathrm{~N}_{\mathrm{CH}} \mathrm{CH}$ & 1.2 & 38.8 \\
\hline $\mathrm{N}-\mathrm{CH}_{2}$ & & \\
\hline 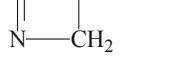 & 3.3 & 45.5 \\
\hline $\mathrm{CH}_{3}$-NH-NC & 4.3 & 45.8 \\
\hline
\end{tabular}

of an aminonitrile that leads to the desired amino acid by hydrolysis. In this spirit, aminoacetonitrile $\mathrm{NH}_{2}-\mathrm{CH}_{2}-\mathrm{CN}$, has been proposed as a possible glycine precursor about thirty years ago (Brown et al. 1977). It was detected two years ago in the direction of Sgr B2 (Belloche et al. 2008).

Whether this detection may be consistent with an energetic criterion has been addressed by an extensive survey of the possible isomers with $\mathrm{C}_{2} \mathrm{H}_{4} \mathrm{~N}_{2}$ chemical formula. From the results reported in Table 6 , it can be seen that the only isomer observed, $\mathrm{NH}_{2}-\mathrm{CH}_{2}-\mathrm{CN}$, is effectively the most stable compound that can be formed. The species containing the $-\mathrm{CN}$ group are more stable than the other isomers. Isonitrile $\mathrm{NH}_{2}-\mathrm{CH}_{2}-\mathrm{NC}$ is $\sim 19 \mathrm{kcal} / \mathrm{mol}$ above its nitrile analogue, which is consistent with the energy differences of $\sim 14$ and $\sim 24 \mathrm{kcal} / \mathrm{mol}$ found for the $\mathrm{HCN} / \mathrm{HNC}$ and $\mathrm{CH}_{3} \mathrm{CN} / \mathrm{CH}_{3} \mathrm{NC}$ couples respectively (Lattelais et al. 2009). Cyclic molecules are once again high in energy, more than $\sim 25 \mathrm{kcal} / \mathrm{mol}$ above the minimum.

\section{Discussion}

The MEP says that the most stable isomer of a given atomic distribution has the largest abundance, and for that reason should be observed first unless dipole moment restrictions oppose the observations. The case of the amide molecules is particularly illustrative. These species are the most stable compounds that can be 
Table A.1. Relative stability (kcal/mol) and dipole moments (Debye) of isomers with same generic formula.

\begin{tabular}{|c|c|c|c|c|c|c|c|}
\hline $\begin{array}{l}\text { Generic } \\
\text { formula }\end{array}$ & $\begin{array}{l}\text { Most stable } \\
\text { isomer }\end{array}$ & $\begin{array}{c}\mu \\
\mathrm{B}^{2} \mathrm{LYP}^{a / b}\end{array}$ & $\begin{array}{l}\text { Other } \\
\text { isomers }\end{array}$ & $\begin{array}{c}\mu \\
\text { B33YP }^{a / b}\end{array}$ & $\begin{array}{c}\Delta E \\
\text { B3LYP }^{a}\end{array}$ & $\begin{array}{c}\Delta E \\
{\text { B } 3 \mathrm{LYP}^{b}}^{\prime}\end{array}$ & $\begin{array}{c}\Delta E \\
\operatorname{CCSD}(\mathrm{T})^{c}\end{array}$ \\
\hline $\mathrm{HCO}^{+}$ & $\mathrm{HCO}^{+}$ & $3.7 / 3.7$ & $\mathrm{HOC}^{+}$ & $2.6 / 2.6$ & 37.3 & 36.7 & 37.9 \\
\hline $\mathrm{HCN}$ & $\mathrm{HCN}$ & $2.9 / 3.0$ & HNC & $3.1 / 3.1$ & 14.3 & 13.6 & 14.5 \\
\hline $\mathrm{C}_{3} \mathrm{H}$ & cyc- $\mathrm{C}_{3} \mathrm{H}$ & $3.6 / 3.6$ & $\mathrm{C}_{3} \mathrm{H}$ & $2.3 / 2.3$ & -1.7 & -1.0 & 1.2 \\
\hline $\mathrm{C}_{3} \mathrm{H}_{2}$ & cyc- $\mathrm{C}_{3} \mathrm{H}_{2}$ & $3.3 / 3.5$ & $1-\mathrm{C}_{3} \mathrm{H}_{2}$ & $4.2 / 4.4$ & 11.1 & 11.8 & 13.7 \\
\hline $\mathrm{HNCO}$ & $\mathrm{HNCO}$ & $2.2 / 2.1$ & $\mathrm{HCNO}$ & $3.1 / 3.2$ & 67.8 & 68.0 & 69.0 \\
\hline \multirow[t]{2}{*}{$\mathrm{C}_{2} \mathrm{H}_{3} \mathrm{~N}$} & $\mathrm{CH}_{3} \mathrm{CN}$ & $3.9 / 4.0$ & $\mathrm{CH}_{3} \mathrm{NC}$ & $3.9 / 3.9$ & 24.1 & 23.5 & 24.3 \\
\hline & & & $\mathrm{CH}_{2} \mathrm{CNH}$ & $1.5 / 1.4$ & 23.5 & 22.1 & 27.1 \\
\hline \multirow[t]{2}{*}{$\mathrm{C}_{2} \mathrm{H}_{4} \mathrm{O}$} & $\mathrm{CH}_{3} \mathrm{CHO}$ & $2.7 / 2.8$ & $\mathrm{CH}_{2} \mathrm{CHOH}$ & $1.0 / 0.9$ & 11.6 & 10.5 & 10.3 \\
\hline & & & cyc- $\mathrm{C}_{2} \mathrm{H}_{4} \mathrm{O}$ & $2.0 / 1.9$ & 30.5 & 29.2 & 27.8 \\
\hline $\mathrm{C}_{2} \mathrm{H}_{6} \mathrm{O}$ & $\mathrm{CH}_{3} \mathrm{CH}_{2} \mathrm{OH}$ & $1.6 / 1.6$ & $\mathrm{CH}_{3} \mathrm{OCH}_{3}$ & $1.3 / 1.2$ & 9.9 & 10.4 & 12.0 \\
\hline \multirow[t]{2}{*}{$\mathrm{HC}_{3} \mathrm{~N}$} & $\mathrm{HC}_{3} \mathrm{~N}$ & $3.8 / 3.9$ & $\mathrm{HC}_{2} \mathrm{NC}$ & $2.9 / 2.9$ & 25.5 & 25.0 & 26.8 \\
\hline & & & $\mathrm{HNC}_{3}$ & $5.4 / 5 / 5$ & 46.0 & 44.8 & 51.4 \\
\hline $\mathrm{C}_{3} \mathrm{H}_{2} \mathrm{O}$ & $\mathrm{HC}_{2} \mathrm{CHO}$ & $2.8 / 2.9$ & cyc- $\mathrm{H}_{2} \mathrm{C}_{3} \mathrm{O}$ & $4.0 / 4.2$ & 4.8 & 5.2 & 6.8 \\
\hline \multirow[t]{2}{*}{$\mathrm{C}_{2} \mathrm{H}_{4} \mathrm{O}_{2}$} & $\mathrm{CH}_{3} \mathrm{COOH}$ & $1.6 / 1.7$ & $\mathrm{HCOOCH}_{3}$ & $1.8 / 1.9$ & 16.0 & 16.1 & 17.1 \\
\hline & & & $\mathrm{HOCH}_{2} \mathrm{CHO}$ & $2.4 / 2.4$ & 28.5 & 27.2 & 27.2 \\
\hline $\mathrm{C}_{4} \mathrm{H}_{3} \mathrm{~N}$ & $\mathrm{CH}_{3}-\mathrm{CC}-\mathrm{CN}$ & $5.2 / 5.3$ & $\mathrm{CH}_{2}=\mathrm{C}=\mathrm{CHCN}$ & $4.3 / 4.4$ & 3.0 & 2.6 & 3.8 \\
\hline $\mathrm{MgNC}$ & $\mathrm{MgNC}$ & $5.2 / 5.3$ & $\mathrm{MgCN}$ & $5.2 / 5.4$ & 1.9 & 2.3 & 1.4 \\
\hline $\mathrm{SiCN}$ & $\mathrm{SiCN}$ & $2.9 / 3.1$ & SiNC & $2.6 / 2.7$ & 1.2 & 1.3 & 1.5 \\
\hline
\end{tabular}

Notes. The first column reports the generic formula of the molecules, ordered in increasing molecular weight. The next two columns report the most stable isomer with its dipole moment; fourth and fifth columns report the less abundant isomer(s) with the relevant dipole moment; Cols. 6 to 8 report the relative stability with respect to the most stable (Col. 2) computed using the three different methods discussed in Sect. 2. ${ }^{(a)}$ Basis set: 6-311G(d,p); ${ }^{(b)}$ Basis set: cc-pVQZ; ${ }^{(c)}$ basis set: cc-pVQZ.

obtained from the $\mathrm{C}_{n} \mathrm{H}_{2 n+1} \mathrm{NO}$ set of atoms. This result has important consequences for exobiology since it shows that the peptide bond, one of the few bonds at the origin of life, is the most stable that can be formed whenever possible. In these conditions, $\mathrm{N}$-methyl formamide, $\mathrm{CH}_{3}-\mathrm{NH}-\mathrm{CHO}$, only $\sim 10 \mathrm{kcal} / \mathrm{mol}$ above acetamide with a dipole moment $\sim 4$ Debye should be the next molecule of this family to search for. With one more carbon in the chain, propanamide appears as the logical candidate; however, detection of the symmetric peptide model, $\mathrm{CH}_{3} \mathrm{CONHCH}_{3}$, that ranks second in the series, would have more implications for exobiology.

The problem with the search for sugars is that these structures are not the most stable that can be formed from the same set of atoms, which is most unfortunate in view of a possible detection. In particular, they are much less stable than the isomers containing a carboxylic function (-COOH). These lowlying hydroxyacids are of utmost interest for future observations, especially lactic acid $\mathrm{HOCH}\left(\mathrm{CH}_{3}\right) \mathrm{COOH}$ (the most stable compound) whose detection would be proof of the existence of chiral molecules in space (even if the D or L configuration could not be established). The application of the MEP to the search for chiral molecules in the ISM can be found in another report devoted to these particular molecules (Marloie et al. 2010).

Detection of dihydroxyacetone, that is doubtful because of the confusion of the lines with those of other species and the lack of some specific lines, is equally questionable for energetic reasons. One may also speculate on an additional reason that would explain the difficulties for observing sugars, namely the presence of the $\mathrm{OH}$ groups that are able to form hydrogen bonds with the grains and maintain a large part of these molecules attached to the surface. Since the OH groups of the hydroxy carboxylic acids present similar inconvenients, dimethyl carbonate $\mathrm{CH}_{3} \mathrm{OCOOCH}_{3}$, although slightly higher on the energy scale, is a candidate to consider since it has no acidic hydrogen for sticking on the grains.
Against this pessimistic view, one may argue that $\mathrm{HOCH}_{2} \mathrm{CHO}$ and $\mathrm{HOCH}_{2} \mathrm{CH}_{2} \mathrm{OH}$ have been observed. In these molecules, there is a strong intramolecular hydrogen bond via a five membered ring structure that decreases the ability to link to an external environment. The same type of internal hydrogen bonding may occur in lactic acid $\mathrm{HOCH}\left(\mathrm{CH}_{3}\right) \mathrm{COOH}$, making this molecule a most appealing target.

Finally, the detection of aminoacetonitrile is an important step that supports the hypothesis of a route to aminoacids via the Strecker synthesis. This route, however, needs also the presence of water and is most probably linked to grain chemistry where $\mathrm{H}_{2} \mathrm{O}$ is brought by the icy mantles.

Looking beyond the energetic considerations at the end of this study, one has to point out the role of ice which, in addition to its capability to provide water, could be crucial for the detection or non detection of a large number of molecules, some being largely depleted on the icy mantles of the grains, others not. In any case, hot environments and shock regions remain the best places to consider for the observation of complex organic molecules.

All the structural details, spectroscopic constants and IR signatures of the various isomers/conformers will be collected in a database document (Lattelais et al. in prep.).

\section{Appendix A:}

Table A.1 lists a series of 14 systems leading to a body of 32 isomers detected in space. The table reports the relative dipole moment of each isomer and stabilities of the different isomers of the same generic formula, computed according to the methods described in Sect. 2. The energy differences between the isomers are very little affected by the level of basis set, and the steady value of the dipole moment is a consistency check of the calculations. The $\operatorname{CCSD}(\mathrm{T})$ values, being the best estimates, have been used as reference for evaluation of the average error bars. 

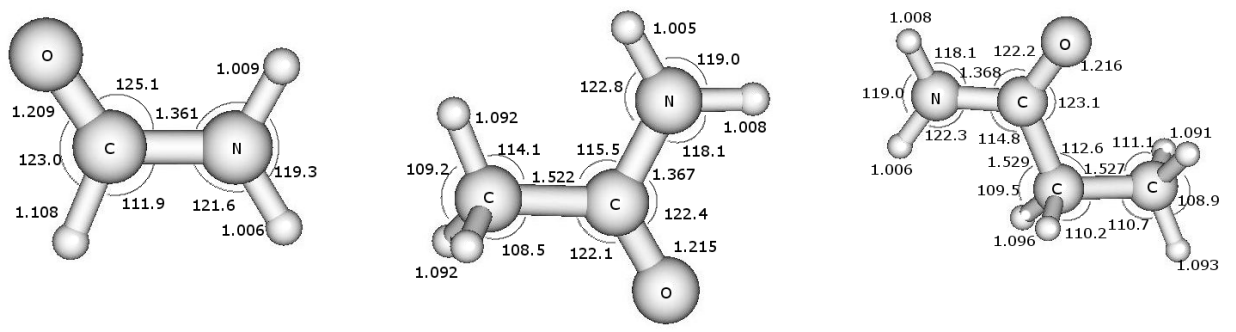

Formamide

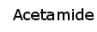

Propanamide
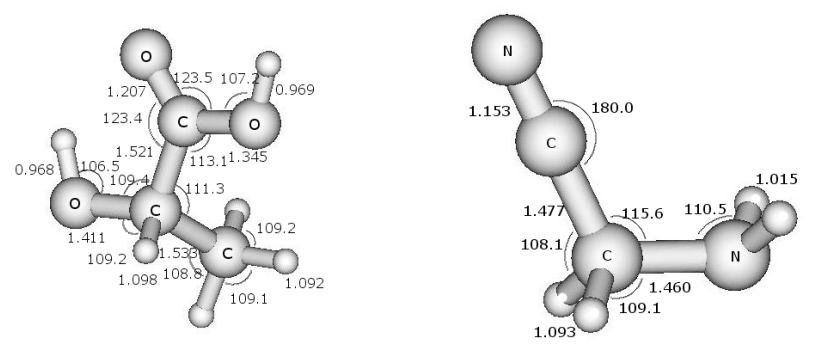

Lactic Acid

Aminoacetonitrile

Fig. B.1. Stable conformations of the most stable species (distances in Ang.; angles in deg.).

\section{Appendix B:}

Figure B.1 shows selected structural parameters of the most stable species presented in the course of the discussion, as obtained after full geometry optimization at the B3LYP/6-311(d,p) level of theory.

Acknowledgements. This work was supported by CNRS national programs PCMI (Physics and Chemistry of the Interstellar Medium), OPV (Origins of Planets and Life) and ANR (Agence Nationale pour la Recherche, contract ANR08-BLAN-0225). Part of the calculations were performed using HPC resources from GENCI-CINES (Grant 2009-085128).

\section{References}

Apponi, A. J., Halfen, D. T., Ziurys, L. M., et al. 2006, ApJ, 643, L29 Ball, J. A., Gottlieb, C. A., Lilley, A. E., \& Radford, H. E. 1970, ApJ, 162, L203 Becke, A. D. 2000, J. Chem. Phys., 98, 5648

Belloche, A., Menten, K. M., Comito, C., et al. 2008, A\&A, 482, 179 Bernstein, M. P., Ashnourn, S. F. M., Sandford, S. A., et al. 2004, ApJ, 601, 365 Bottinelli, S., Ceccarelli, C., Williams, J. P., \& Lefloch, B. 2007, A\&A, 463, 601 Brown, R. D., Crofts, J. G., Godfrey, P. D., et al., 1975, ApJ, 197, L29

Brown, R. D., Godfrey, P. D., Ottrey, et al., 1977, J. Mol. Spectr, 68, 359 Chiaramello, J. M., Talbi, D., Berthier, G., \& Ellinger, Y. 2005, Int. J. Astrobiol., 4, 125

Cooper, G. W., Onwo, W. M., \& Cronin, J. R. 1992, Geochim. Cosmochim. Acta, 54,4109

Ehrenfreund, P., Glavin, D. P., Botta, O., et al. 2001, PNAS, 98, 2138

Frisch, M., Trucks, G., \& Schlegel, H. 2004, Gaussian 03, Rev.C.02, Gaussian Inc., Wallingford CT., 611, 605
Hollis, J. M., Lovas, F. J., \& Jewell, P. R. 2000, ApJ, 540, L107

Hollis, J. M., Remijan, A. J., Jewell, P. R., \& Lovas, F. J. 2006a, ApJ, 642, 933

Hollis, J. M., Lovas, F. J., Remijan, A. J., et al. 2006b, ApJ, 643, L25

Ikeda, M., Ohishi, M., Nummelin, A., et al. 2001, ApJ, 560, 792

Koch, W., \& Holthausen, M. C. 2001, A Chemist Guide to Density Functional Theory, 2nd edn (Weinheim, Germany: Wiley-VCH)

Lattelais, M., Pauzat, F., Ellinger, Y., et al.. 2009, ApJ, 696, L133

Lee, C., Yang, W., \& Parr, R. G. 1988, Phys. Rev. B, 37, 785

Lee, T. J., \& Scuseria, G. E. 1995, In Quantum mechanical electronic structure calculations with chemical accuracy, ed. Langhoff, S. R. (Dordrecht, The Netherlands: Kluwer Academic Publishers)

Marloie, G., Lattelais, M., Pauzat, F., Pilmé, J., \& Ellinger, Y. 2010, Interdiscip. Sci. Comput. Life Sci., 2, 1

Martin, J. M. L., El-Yazal, J., \& Francois, J. 1996, J. Phys. Chem., 100, 15358

Mehringer, D. M., Snyder, L. E., Miao, Y., \& Lovas, F. J. 1997, ApJ, 480, L71

Peltzer, E. T., Bada, J. L., Schlesinger, G., et al. 1984, Adv. Space Res., 4, 69

Puletti, F., Malloci, G., Mulas, G., \& Cecchi-Pestellini, C. 2010, MNRAS, 402 , 1667

Requena-Torres, M. A., Martín-Pintado, J., Rodríguez-Franco, A., et al. 2006, A\&A, 455, 971

Rubin, R. H., Swenson, Jr., G. W., Benson, R. C., Tigelaar, H. L., \& Flygare, W. H. 1971, ApJ, 169, L39

Snyder, L. E., Buhl, D., \& Palmer, P. 1969, Phys. Rev. Lett., 22, 679

Solomon, P. M., Jefferts, K. B., Penzias, A. A., \& Wilson, R. W. 1971, ApJ, 168, L107

Turner, B. E. 1971, ApJ, 163, 35

Wesolowski, T. A. 2000, J. Chem. Phys., 113, 1666

Wesolowski, T. A., Parisel, O., Ellinger, Y., \& Weber, J. 1997, J. Phys. Chem. B, 101,7818

Widicus Weaver, S. L., \& Blake, G. A. 2005, ApJ, 624, L33

Zhang, Y., Pan, W., \& Yang, W. 1997, J. Chem. Phys., 107, 7921

Zuckerman, B., Ball, J. A., \& Gottlieb, C. A. 1971, ApJ, 163, L41 